\title{
OBSERVATIONS OF INTERNAL RELAXATION OSCILLATIONS IN THE ADIABATIC TOROIDAL COMPRESSOR
}

BY

R. R, SMITH

\section{PLASMA PHYSICS LABORATORY}

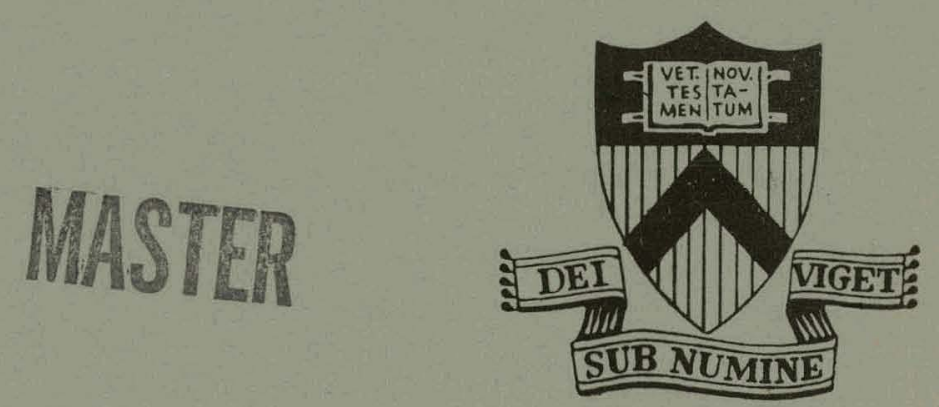

\section{PRINCETON \\ UNIVERSITY PRINCETON, NEW JERSEY}

This work was supported by U. S. Energy Research and Development Administration Contract E(11-1)-3073. Reproduction, translation, publication, use and disposal, in whole or in part, by or for the United States Government is permitted. 


\section{DISCLAIMER}

This report was prepared as an account of work sponsored by an agency of the United States Government. Neither the United States Government nor any agency Thereof, nor any of their employees, makes any warranty, express or implied, or assumes any legal liability or responsibility for the accuracy, completeness, or usefulness of any information, apparatus, product, or process disclosed, or represents that its use would not infringe privately owned rights. Reference herein to any specific commercial product, process, or service by trade name, trademark, manufacturer, or otherwise does not necessarily constitute or imply its endorsement, recommendation, or favoring by the United States Government or any agency thereof. The views and opinions of authors expressed herein do not necessarily state or reflect those of the United States Government or any agency thereof. 


\section{DISCLAIMER}

Portions of this document may be illegible in electronic image products. Images are produced from the best available original document. 
NOTICE

This report was prepared as an account of work sponsored by the United States Government. Neither the United States nor the United States Energy Research and Development Administration, nor any of their employees, nor any of their contractors, subcontractors, or their employees, makes any warranty, express or implied, or assumes any legal liability or responsibility for the accuracy, completeness or usefulness of any information, apparatus, product or process disclosed, or represents that its use would not infringe privately owned rights.

Printed in the United States of America. Available from

National Technical Information Service

U. S. Department of Commerce 5285 Port Royal Road

Springfield, Virginia 22151

Price: Printed Copy $\$ \star * ;$ Microfiche $\$ 1.45$

*Pages

$$
1-50
$$

$51-150$

$151-325$

326-500

501-1000
NTIS

Selling Price

$\$ 4.00$

5.45

7.60

10.60

13.60 
OBSERVATIONS OF INTERNAL RELAXATION OSCILLATIONS

IN THE ADIABATIC TOROIDAL COMPRESSOR

\author{
R. R.-SMITH \\ Plasma Physics Laboratory, Princeton University \\ Princeton, New Jersey. 08540
}

\title{
ABSTRACT
}

The soft $x$ ray signal from the Adiabatic Toroidal Compressor (ATC) sometimes exhibits a 10\% modulation with a frequency between 1 and 2 Kilohertz. The radial profile of the soft $x$ ray signal and the electron temperature determined by laser scattering indicate that these fluctuations are associated with a limitation of the central electron temperature and a broadening of the temperature profile. By observing changes in the radial dependence of the relaxation oscillation during neutral injection, an increase of thirty to fifty percent in the radius where $q=1$ has been measured.

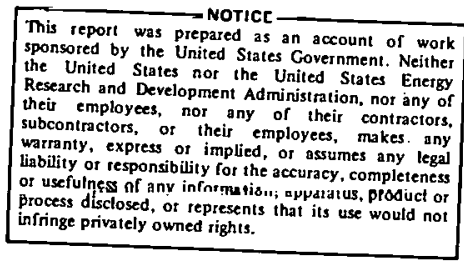




\section{INTRODUCTION}

At several tokamak installations around the world, including $S T^{[1]}, A T C^{[2]}, \operatorname{TFR}^{[3]}$, and $T-4^{[4]}$, the plasma nearest the magnetic axis has been observed to possess an instability which results in a periodic modulation of the emitted soft $x$ rays under suitable experimental conditions. This instability does not destroy the confinement of the plasma as a whole, because it is common for several tens of relaxation periods to occur ill suivession. This instability dọes not occur in ATC at the same time as a saturated $m-2$ instability, and a particular discharge may pass from one mode of instability to the other. At ST, the mode numbers of this modulation have been shown to be $m=0, n=0$, with an additional faster modulation characterized by $m=1, n=1$. This fast modulation, which has a frequency near $15 \mathrm{KHz}$ on ATC, grows to a maximum just before an abrupt decrease in the signal from the center of the plasma. The detailed shape of this relaxation or sawtooth instability provides information near the center of tokamak plasmas which supplements the information provided by the variations with radius and time of the average detector signal.

At $S T$ and $T F R$, it has been shown that the radius where $q=1$, calculated from the Thomson scattering data, has a definite relationship to the form of the modulation as a 
function of the viewed chord through the plasma. This reationship is illustrated in Fig. 1, a schematic representation of the two detector system used in these experiments. Consider one detector with the line of sight shown and three positions for the $q=1$ surface. As the $q=1$ surface moves out to touch and then to include the viewed chord, the slow modulation has the following forms: an abrupt rise followed by a slow decrease, a series of impulses at the point of tangency, and a slow increase followed by an abrupt decrease when looking through the magnetic axis. This relation between the $q=1$ surface and the shape of the modulation can be used to examine changes in the current profile even without a complete theoretical understanding of the instability.

After a discussion of the experimental method, the time variations of the plasma density and central electron temperature will be compared with the $\mathrm{x}$ ray signals observed along different chords and at two values of limiter $q$. The instability is believed to depend upon a competition between the peaking of the central electron temperature and current density on the one hand, and on the growth of the internal kink mode $[5]$, on the other hand. An experimental attempt to influence this competition and its resulting relaxation oscillations will be described. 


\section{EXPERIMENTAL TECHNIQUES}

The detectors used in these experiments were partially depleted silicon surface barrier detectors with an area of $0.5 \mathrm{~cm}^{2}$ and a depletion depth of 100 microns. They could be moved independently and vertically, and they looked through a common horizontal beryllium window with dimensions $2 \mathrm{~cm} \times 0.24 \mathrm{~cm} \times: 25 \mathrm{microns}$. The distances between the detectors and the window and between the window and the magnetic axis were $25 \mathrm{~cm}$ and $60 \mathrm{~cm}$, respectively. As in the ST experiments, the space between the window and the detectors was filled with one atmosphere of Helium to prevent excessive signal attenuation. The detected photons with energies between

1.5 and $10.0 \mathrm{KeV}$ produced a direct current of one charge pair per $3.6 \mathrm{eV}$ of energy deposited in the depletion region. The spatial resolution at the magnetic axis was approximately one $\mathrm{cm}$. The measured current was the product of the detector system sensitivity and the source power integrated over frequency and path length through the plasma.

III. RELAXATION OSCILLATIONS AND THE AVERAGE X RAY SIGNAL

Five milliseconds after the initiation of the discharge, the typical soft $x$ ray signal from the center of ATC began to rise. After ten milliseconds, the relaxation oscillations appeared and there was an abrupt decrease in the rate of rise of the signal. The amplitude decreased slightly and then continued to rișe at a slower rate than before the appearance of the relaxation oscillations. Most of the increase in the 
amplitude can be explained by the increase in plasma density. This is shown in Fig. 2, which compares the central $x$ ray signal, line averaged density, and the ratio of signal to the square of the density. For this and succeeding figures, " $\mathrm{T}=0 "$ occurs six milliseconds before the initiation of the current. The experimental conditions were the same as were used to obtain Fig. 4 and part of Fig. 3.

The abrupt decrease in the growth of the central $x$ ray signal was associated with a saturation of the central electron temperature measured by Thomson scattering. In Fig. 3 we see a comparison of these two quantities for two values of $q$ at the limiter $\left(\mathrm{aB}_{\mathrm{T}} / \mathrm{RB}_{\mathrm{p}}\right)$. There were Thomson scattering data only for the initial part of the discharge, as shown. When the toroidal field was increased from $15 \mathrm{KG}$ to $20 \mathrm{KG}$ and the plasma current reduced from $80 \mathrm{KA}$ to $60 \mathrm{KA}$, the limiter $q$ value increased from 2.8 to 5 and the central $x$ ray signal lost both its relaxation oscillations and its abrupt decrease in its rate of rise. With this increased limiter $q$, the central electron temperature increased steadily during the initial part of the discharge.

The $x$ ray signal observed along other chords also showed abrupt changes when the relaxation oscillations appeared. Fig. 4 shows the comparison of the signals from lines of sight tangent to radii of $1.5,4.5,6$, and $7.5 \mathrm{~cm}$. The central signal behaved as described above, but at the time that the relaxation oscillations appeared, there was an abrupt increase in the power 
emitted from radii of one third to one half the liniter radius. The upper traces are from an adjacent detector covered with an additional filter of twenty five mićron thick aluminum. Although the present system was not capable of measuring the plasma temperature due to the very thin beryllium foil that was used, it is clear that the higher energy photon emission during the discharge increased much more at large radii than at small radii. This effect was not observed for the case of higher limiter $q$.

The phenomena described in Figs. 2, 3, and 4 suggest that the observed relaxation oscillations limit the central temperature of ATC and redistribute the plasma energy to larger radii. The emitted power also depends strongly upon. the impurity content of the plasma. The simplest assumption for the source of the radiation is Bremsstrahlung, for which the power per frequency interval is proportional to $\mathrm{n}_{e}^{2} \mathrm{Z}_{\operatorname{eff}} \mathrm{T}^{-1 / 2} \exp \left(-\mathrm{h}^{-1 / K \mathrm{~T}_{e}}\right)$. However, it is known that the radiation is stronger than predicted by Bremsstrahlung and is believed to be due to recombination radiation $[6,7]$ which depends more strongly upon the impurity charge: Because the central temperature is nearly constant and the temperature profile is apparently broadening, the near proportionality between the $x$ ray signal and the square of the density in Fig. 2 suggests that the relative impurity concentration does not change significantly during the time of these data.

Such a broadened temperature profile was difficult to, confirm with the laser $\mathrm{T}_{\mathrm{e}}$ data because of their large error 
bars as shown in Fig. 3. However, one particular set of data, two laser profiles near fifteen and thirty milliseconds in the discharge did show a decreased central temperature and a broadened temperature profile after the appearance of the relaxation oscillations. The temperature profiles at these two times could be approximated by $1550 \exp \left[5.87(r / 16)^{2}\right]$ and $1100 \exp \left[-2.46(r / 16)^{2}\right]$, respectively. Because the temperature at $6 \mathrm{~cm}$ was nearly $700 \mathrm{eV}$ and the detectors were insensitive to photons of energy less than $1.5 \mathrm{KeV}$, a $100 \mathrm{eV}$ variation in an original electron temperature of $700 \mathrm{eV}$ would cause a large change in signal. Thus the $\mathrm{x}$ ray signal was quite sensitive to changes in the sloping region of the temperature profile which were difficult to measure with the laser system on ATC. As mentioned above, the radial profiles of $q$ inferred from the temperature profiles and the assumption that the current density is proportional to $\mathrm{T}_{\mathrm{e}}^{3 / 2}$ were in good agreement with the location of the $q=1$ surface determined by the $x$ ray modulation in the experiments performed on $S T$ and TFR. This was not true on ATC, where the $\mathrm{q}=1$ radius determined by the laser was typically 7 to $9 \mathrm{~cm}$, while the $x$ ray modulation implied a radius of about $3 \mathrm{~cm}$. One can resolve the discrepancy by postulating an enhanced resistivity near the magnetic axis. Preliminary experiments with a multi-channel microwave interferometer detected density fluctuations within three or. four $\mathrm{cm}$ of the magnetic axis, supporting the $\mathrm{x}$ ray data ${ }^{[8]}$. Such measurements of the $q=1$ radius by means of the $x$ ray modulation have also been made during neutral injection experiments on ATC. 
IV. X RAY MODULATION DURING NEUTRAL INJECTION

The neutral injection experiments used a Lawrence Berkeley Laboratory source with curved grids to increase the fraction of beam transmitted into ATC. The beam power was measured on a calorimeter at the end of the neutralization tube and about one meter from the vacuum chamber. Suitable corrections for beam geometry and partial neutralization were applied.

Such a neutral beam is primarily intended to heat the plasma ions. However, a more subtle effect can be seen in Fig. 5, which shows the modification of the form of the soft $\mathrm{x}$ ray modulation caused by the counter injection into $a$ hydrogen plasma of a $65 \mathrm{KW} 15 \mathrm{KeV}$ deuterium beam. In this figure, there are four pairs of traces in the left column with the neutral beam on and four pairs in the right column with the beam off. Each pair of traces is from two detectors located symmetrically with respect to the machine midplane. The distance which each detector has been moved is shown next to each pair of traces. In these units, "100" corresponds to a line of sight passing approximately $3 \mathrm{~cm}$ above the magnetic axis for one detector and $3 \mathrm{~cm}$ below this axis for the other detector. The increased detector displacement which was needed with the beam to obtain a modulation similar in shape to that without the beam is evidence for an outward shift of the $q=1$ surface by 1 to $1.5 \mathrm{~cm}$. The "Beam On" signal differs 
from the "Beam off" signal because of the increase in several quantities: the amplitudes of the average $x$ ray signal and of its modulation, the period of the relaxation modulations, and the frequency of the $\mathrm{m}=1$ modulation. These changes are very evident even at the end of the discharge, ten milliseconds after the end of injection.

For these experiments, the electron density at the end of the lomsec injection pulse was increased above the value with no injection from a line average of $1.4 \times 10^{13} \mathrm{~cm}^{-3}$ to $1.8 \times 10^{13} \mathrm{~cm}^{-3}$. The average $\mathrm{x}$ ray signal was nearly porportional to the square of the electron density with or without injection, although the relative amplitude of 'relaxation oscillations was roughly fifty per cent larger in the case of injection. No significant changes in electron temperature due to neutral injection were observed with laser scattering. The period of the relaxation oscillations normally increases by roughly fifty per cent during a discharge, and the present neutral injection experiment caused an additional sixty per cent increase. The frequency increase of the $\mathrm{m}=\mathrm{l}$ codulation is in the direction appropriate for a doppler shift, due to toroidal rotation, of the oscillations manifesting the electron diamagnetic drift. When comparing the frequency shifts of the $m=1$ oscillations observed by $x$ rays and the $m=2$ oscillations observed by external coils, under somewhat different experimental conditions, the frequency shifts were in opposite directions for co and counter-injection and implied a toroidal rotation speed of $5 \times 10^{5} \mathrm{~cm} \mathrm{sec}-1$. The $\mathrm{m}=1$ modulation is 
quite clear on the upper left pair of traces in Fig. 5, and the odd $m$ character of the instability can be seen from the phase relation between the traces. From this picture, a plot of the logarithm of the peak-to-peak amplitude for each half cycle gives a growth rate of $7 \times 10^{4} \mathrm{sec}^{-1}$ for a plasma line average density of $1.8 \times 10^{13} \mathrm{~cm}^{-3}$ hydrogen, a toroidal magnetic field of 15 Kilogauss, a plasma current of 70 Kiloamps, and major and minor radii of 85 and $16 \mathrm{~cm}$. The ion and electron temperatures were not measured, but they were probably near the typical ATC peak values with injection of $250 \mathrm{eV}$ and $1200 \mathrm{eV}$, respectively. Using the formula for the growth rate given in Ref. 1 , one obtains a predicted $\gamma$ of $1.2 \times 10^{5} \sec ^{-1}$ for these experimental parameters.

The effects during neutral injection were not duplicated by the addition of $\mathrm{D}_{2}$ gas during a deuterium discharge by means of a fast pulse,valve. At a time when the pulse valve increased the line average density from $1.5 \times 10^{13}$ to $1.9 \times 10^{13} \mathrm{~cm}^{-3}$, an existing relaxation oscillation increased its period for one or two periods, and then the discharge changed modes so that there was a large $m=2$ oscillation. The density increase occurred over three milliseconds with the pulse valve and over ten milliseconds with injection. It is possible that neutral injection produced the above effects by modifying the impurity concentration and distribution. This would be especially likely for counter-injection, which has a greater proportion of uncontained fast ions. However, the 
proportionality between the signal and the square of the density implies that any additional impurities caused by injection only occupied the outer, cooler regions of the plasma which do not emit much $x$ ray power.

An increase in the relaxation period of about fifty per cent was also observed for co-injection but without a change in the $\mathrm{q}=1$ location. This is in spite of co-injection's greater effectiveness for heating the plasma and its higher concentra tion of hot ions near the magnetic axis. Thus it is plausible that counter-injection shrinks the temperature profile by an increase of impurities near the plasma boundary and thereby changes the radius where $q=1$.

\section{CONCLUSIONS}

Relaxation oscillations near the magnetic axis of ATC have been studied by observing soft $\mathrm{x}$ ray radiation. The electron temperature measured with Thomson scattering and the soft $\mathrm{x}$ ray signal through different chords were compared for discharges with and without relaxation oscillations by varying the limiter $q$ values. The presence of the instability was associated with a broader distribution of plasma energy and a central electron temperature which did not increase after the oscillations appeared. The relaxation oscillations were modified by neutral injection, and the radius of the $q=1$ surface determined from the $x$ ray signal was increased by 30 
to 50 per cent, although this was, probably caused be an increase of impurities at the edge of the plasma.

\section{ACKNOWLEDGMENTS}

The author is grateful for the help and information provided by $S$. von Goeler and also for the interest shown by R. Ellis in these experiments. He is also indebted to H. Eubank for the ATC neutral injection system, to $C$. C. Daughney for the Thomson scattering measurements and for help with the preparation of this manuscript, and to $\mathrm{K}$. Bol for the toroidal velocity measurements.

The work was supported by United States Energy Research and Development Administration (formerly AEC) Contract E(11-1)3073. . 


\section{REFERENCES}

[1] VON GOELER, S., STODIEK, W., and SAUTHOFF, N., Phys. Rev. Letters, 23 (Nov. 1974) 1201-1203.

[2] SMITH, R. R., Bull. Am. Phys. Soc. (Oct. 1974) 884 .

[3] TACHON, J., Annual Mt. Theoretical Aspects of Controlled Therm. Research, N.R.A., Washington, D. C., (Apr. 1975) paper AI.

[4] VERSHKOV, V. A., LISENKO, E., SEMENOV, I. B., and SCHERBAC, A. T., Kurchatov Instatute Report 1AE-2291 (1973).

[5] ROSENBLUTH, M., DAGAzIAN, R., and RUTHERFORD, P., Phys. Fluids, 16, (1973) 1894 .

[6] VON GOELER, S., STODIEK, W. , FISHMAN, H., GREBENSHCHIKOV, S., and HINNOV, E., Matt-1081.

[7] VERShKOV, V. A., MIRNOV, S. V., Nuc. Fusion 14 (1974) 383.

[8] GRISHAM, L., private communication. 


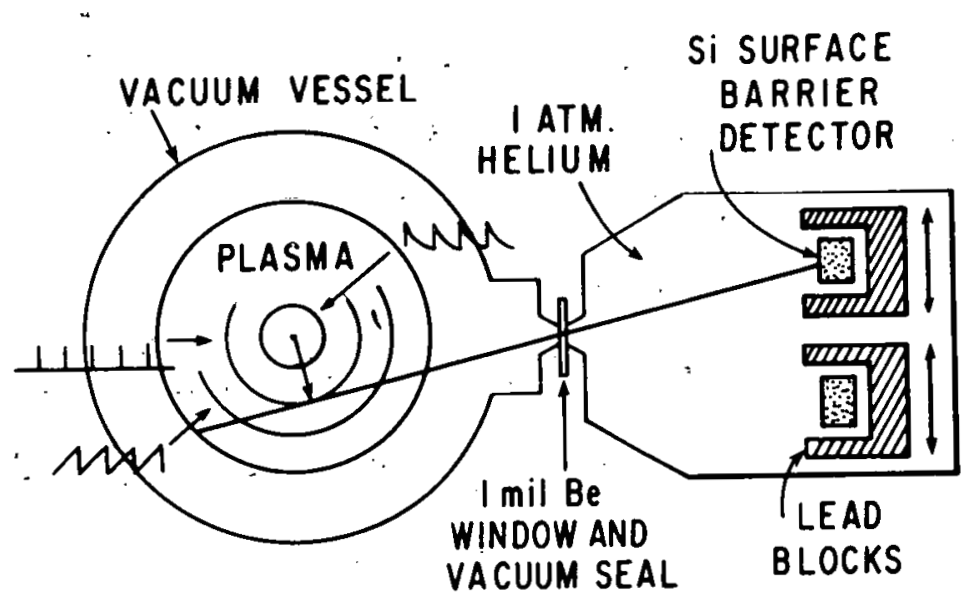

753566

Fig. 1. A schematic drawing, not to scale, of the relation between detector position, location of the $q=1$ surface, and the detailed shape of the modulation of the detector signal.

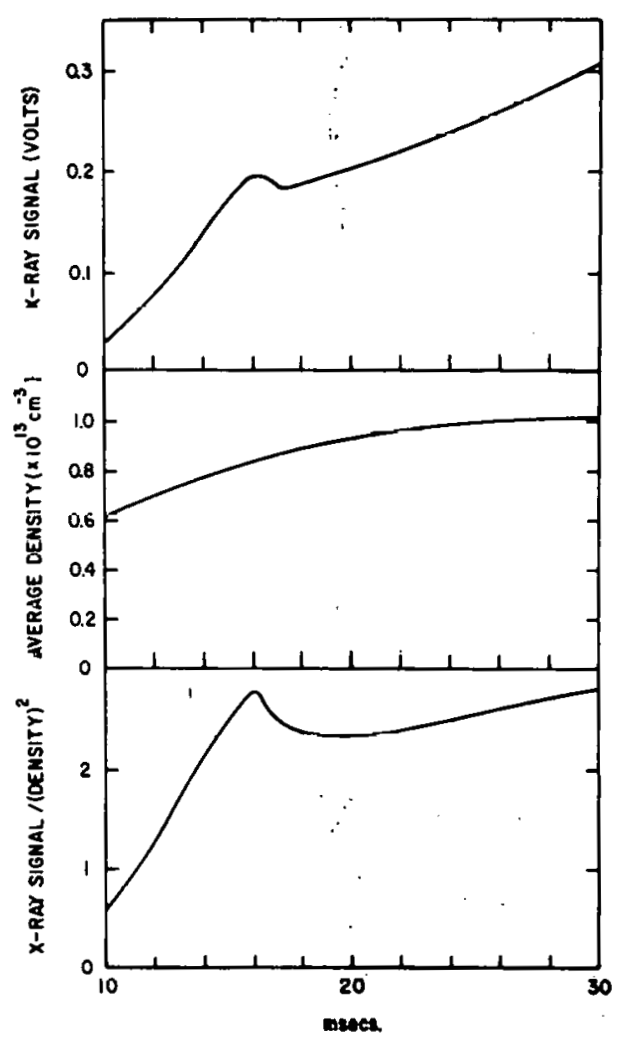

\section{7}

Fig. 2. A comparison of the detector signal averaged over the oscillation periods, the line averaged plasma density, and the ratio of signal to square of the density during the constant plasma current phase of an ATC discharge with relaxation oscillations. The discharge is initiated at six milliseconds. 

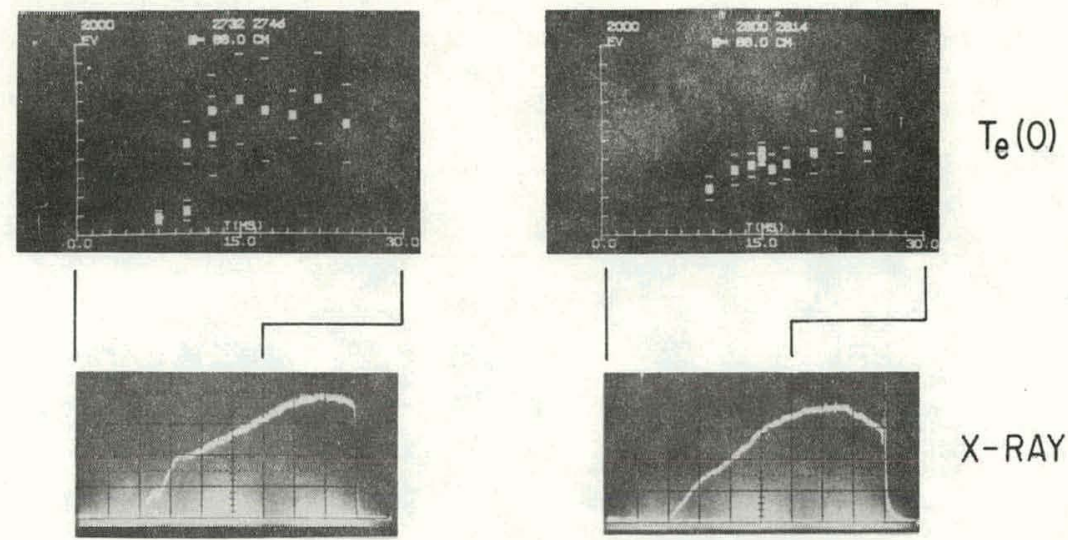

$$
q(a)=2.8
$$

$q(a)=5.0$

753568

Fig. 3. The time variations of central electron temperature as measured by laser scattering and of the x-ray detector signal are compared for two values of limiter $q$. For the lower $q$ value, a sharp change in the rate of rise of the $x-r a y$ signal occurs near the time that the central temperature ceases to rise.

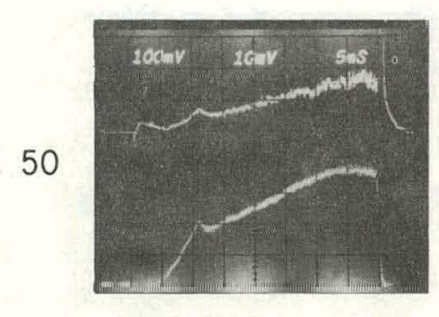

150
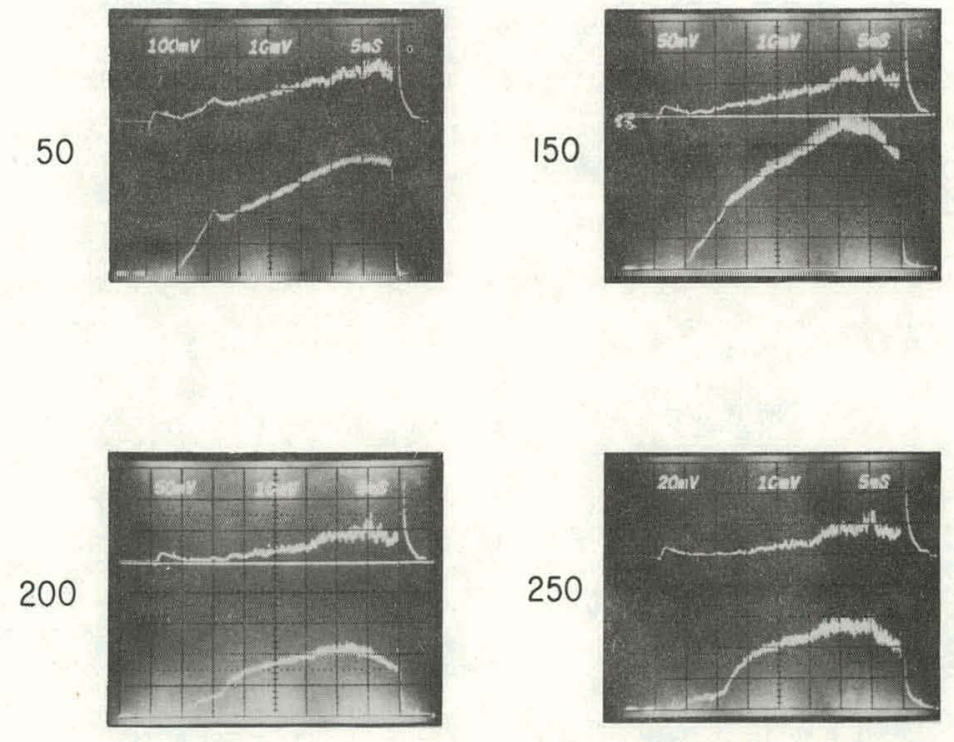

753567

Fig. 4. The x-ray signals obtained from different chords for the experimental conditions $q(a)=2.8$ in Fig. 3. The four pairs of traces are for view lines tangent to radii of 1.5 , $4.5,6$, and $7.5 \mathrm{~cm}$ from the magnetic axis. The upper traces in each pair are from a detector covered by an aluminum foil of $25 \mu$ thickness. 
BEAM ON
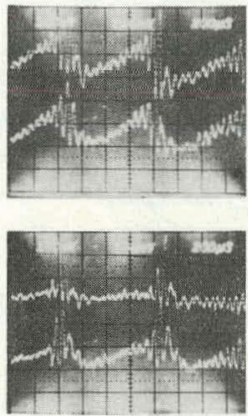

150

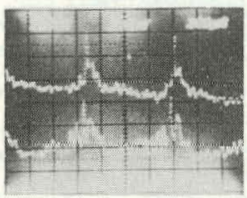

200

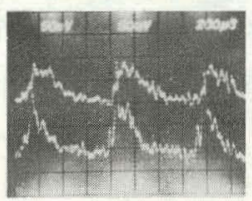

BEAM OFF

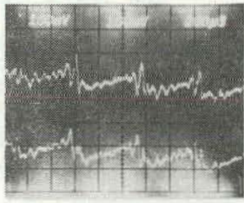

50

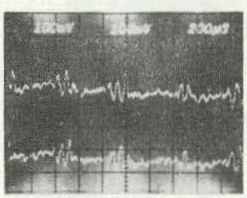

80

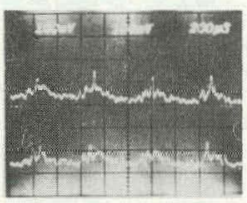

120

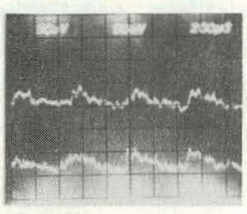

200

753569

Fig. 5. The x-ray signals obtained from different chords are shown for four detector positions without neutral injection on the right and for four positions with injection on the left. Each pair of traces is from symmetric displacements of the two detectors above and below the machine midplane. The changes caused by injection include an outward displacements of the q-1 surface, a lengthening of the sawtooth period, and an increase in the $\mathrm{m}=1$ modulation frequency. 